\title{
Immuno-PET of Innate Immune Markers CD11b and IL-1 $\beta$ Detects Inflammation in Murine Colitis
}

\author{
Nicole Dmochowska ${ }^{1}$, William Tieu ${ }^{2}$, Marianne D. Keller ${ }^{1,3}$, Hannah R. Wardill ${ }^{1}$, Chris Mavrangelos ${ }^{1}$, \\ Melissa A. Campaniello ${ }^{1}$, Prab Takhar ${ }^{2}$, and Patrick A. Hughes ${ }^{1}$ \\ ${ }^{1}$ Centre for Nutrition and Gastrointestinal Diseases, Adelaide Medical School, University of Adelaide and South Australian Health \\ and Medical Research Institute, Adelaide, Australia; ${ }^{2}$ Molecular Imaging and Therapy Research Unit, South Australian Health and \\ Medical Research Institute, Adelaide, Australia; and ${ }^{3}$ Preclinical, Imaging, and Research Laboratories, South Australian Health and \\ Medical Research Institute, Adelaide, Australia
}

Inflammatory bowel disease (IBD) is a chronic relapsing and remitting inflammatory disease of the gastrointestinal tract. The diagnosis and monitoring of IBD are reliant on endoscopy, which is invasive and does not provide information on specific mediators. Symptom flare in IBD is associated with increased activation of innate immune pathways. Immuno-PET approaches have previously demonstrated the ability to detect colitis; however, a direct comparison of antibodies targeted to innate immune mediators and cells has not been done. We aimed to compare immuno-PET of antibodies to IL-1 $\beta$ and CD11b against standard ${ }^{18} \mathrm{~F}-\mathrm{FDG}$ and MRI approaches to detect colonic inflammation. Methods: Colonic concentrations of $\mathrm{IL}-1 \beta$ and myeloperoxidase were determined by ELISA, and colonic infiltration by CD11b-positive CD3-negative innate immune cells was determined by flow cytometry and compared between healthy and dextran sodium sulphate-treated colitic mice. PET of ${ }^{89} \mathrm{Zr}$-la-IL-1 $\beta,{ }^{89} \mathrm{Zr}-\mathrm{a}-\mathrm{CD} 11 \mathrm{~b}$, and ${ }^{18} \mathrm{~F}-\mathrm{FDG}$ was compared by volume-of-interest analysis and with MRI by region-of-interest analysis. Imaging results were confirmed by ex vivo biodistribution analysis. Results: Colonic inflammation was associated with impaired colonic epithelial barrier permeability, increased colonic IL-1 $\beta$ and myeloperoxidase concentrations, and increased CD11b-positive CD3-negative innate immune cell infiltration into the colon. ${ }^{89} \mathrm{Zr}-\mathrm{a}-\mathrm{IL}-1 \beta$ and ${ }^{89} \mathrm{Zr}$ - $\mathrm{a}-\mathrm{CD} 11 \mathrm{~b}$ immuno-PET detected colonic inflammation, as did ${ }^{18} \mathrm{~F}-\mathrm{FDG}$, and all PET tracers were more sensitive than MRI. Although ${ }^{18} \mathrm{~F}-\mathrm{FDG}$ volumes of interest correlated with colitis severity and a strong trend was observed with ${ }^{89} \mathrm{Zr}-\mathrm{a}-$ IL-1 $\beta$, no correlation was observed for ${ }^{89} \mathrm{Zr}$ - $\mathrm{a}-\mathrm{CD} 11 \mathrm{~b}$ or MRI. ${ }^{89} \mathrm{Zr}-\alpha-\mathrm{IL}-1 \beta$ was distributed mainly to the gastrointestinal tract, whereas ${ }^{89} \mathrm{Zr}$-a-CD11b was distributed to more tissue types. Conclusion: Immuno-PET using antibodies directed to innate immune markers detected colonic inflammation, with ${ }^{89} \mathrm{Zr}$ - $\mathrm{a}-\mathrm{IL}-$ $1 \beta$ providing a more tissue-specific signal than ${ }^{89} \mathrm{Zr}$ - $\mathrm{a}-\mathrm{CD} 11 \mathrm{~b}$. Development of these technologies for human subjects will potentially provide a less invasive approach than endoscopy for diagnosing and monitoring IBD.

Received Aug. 22, 2018; revision accepted Oct. 22, 2018

For correspondence or reprints contact: Patrick A. Hughes, Centre for Nutrition and Gastrointestinal Diseases, Level 7 SAHMRI, Adelaide, South Australia, 5000, Australia.

E-mail: patrick.hughes@adelaide.edu.au

Published online Nov. 9, 2018.

COPYRIGHT (c) 2019 by the Society of Nuclear Medicine and Molecular Imaging.
Key Words: immuno-PET; innate immune system; colitis; inflammatory bowel disease

J Nucl Med 2019; 60:858-863

DOI: 10.2967/jnumed.118.219287

I flammatory bowel disease (IBD) is a collection of chronic idiopathic inflammatory diseases of the gastrointestinal tract, including Crohn disease and ulcerative colitis (1). IBD substantially affects quality of life, and although treatable, significant gaps remain because of incomplete efficacy, lack of tolerance, and side effects, leading to variable periods of remission and relapse (2). Patients with IBD require constant surveillance because prognostic indicators of symptom flare remain poor and patients with long-standing disease have an increased risk of developing colon cancer $(2,3)$. The diagnosis and management of IBD are currently heavily reliant on endoscopy, which is generally well tolerated but is invasive, is restricted to imaging of the superficial mucosal surface, cannot easily reach all areas of the small intestine, and does not provide immediate information on specific mediators or mechanisms. Therefore, new technologies are required for imaging IBD that are less invasive than endoscopy and can provide information on specific pathologic processes in real time.

Clinical studies support the use of PET, SPECT, and MRI for detecting inflammation in the gastrointestinal tract, satisfying the criteria for reduced invasiveness and real-time information $(4,5)$. However, current clinical PET, SPECT, and MRI approaches in IBD are restricted to using radiolabeled autologous leukocytes and ${ }^{18}$ F-FDG in PET and SPECT and using gadolinium contrast in MRI, none of which provides information on specific mediators. This lack of detail is of increasing importance because of the increase in use of target-specific biologics, particularly antibodies, and the emergence of personalized medicine.

Monoclonal antibodies have exquisite selectivity for their target, and their applicability to immuno-PET has been appreciated for decades, particularly in the cancer field (6-8). However, the use of immuno-PET in IBD is currently limited to preclinical studies, in which T-cell infiltration into the colon of colitic animals has been demonstrated either directly by imaging the $\mathrm{T}_{\text {HELPER }}$ cell marker CD4 (9) or indirectly by targeting the gut-homing integrin $\alpha_{4} \beta_{7}$ (10). In contrast, immuno-PET of immune mediators is yet to be reported; however, direct labeling of the neutrophil-attracting 
chemokine CXCL8 (also known as IL-8) $(11,12)$ and antibodydirected imaging of TNF- $\alpha$ (13) have shown some efficacy for SPECT in both colitic animals and human IBD.

Activation of the innate immune system is intimately linked to inflammation in IBD, most obviously illustrated by the clinical utility of detection of the neutrophil-secreted mediators calprotectin and lactoferrin in stool (3). IL-1 $\beta$ is an inducible cytokine that has a key role in innate immune responses and is predominantly secreted by neutrophils, monocytes, macrophages, and dendritic cells, whereas $\mathrm{CD} 11 \mathrm{~b}$ is a pan-myeloid innate immune marker predominantly expressed on these same cell types. Here, we aimed to compare the ability of PET of ${ }^{89} \mathrm{Zr}$-conjugated antibodies against IL- $1 \beta$ and CD11b with the ability of standard $\left({ }^{18} \mathrm{~F}\right.$ FDG) PET and MRI to detect inflammation in colitic mice.

\section{MATERIALS AND METHODS}

All experiments were approved by the Animal Ethics Committee of the South Australian Health and Medical Research Institute (SAHMRI) and the University of Adelaide.

\section{Mice}

Male C57BL/6jSah mice aged 10-14 wk (20-30 g) were bred and group-housed in a specific pathogen-free environment at SAHMRI. Animals had ad libitum access to food and water. Experiments were conducted with only male mice to eliminate the potential confounding effects of the estrous cycle. Mice were humanely euthanized via $\mathrm{CO}_{2}$ inhalation and cervical dislocation to remove tissues.

\section{DSS Colitis Model}

Colitis was induced by replacing normal drinking water with $2 \%$ (w/v) dextran sodium sulphate (DSS) (molecular mass, 40-50 kDa; Alfa Aesar) for $5 \mathrm{~d}$, followed by an additional $3 \mathrm{~d}$ of normal drinking water. Mice were assessed daily for signs of acute colitis, including a decrease in body weight and diarrhea. Healthy mice were age- and weight-matched. Colon length was measured on excised colons dissected free from surrounding tissue from the tip of the anus to the distal end of the cecum.

\section{Ussing Chamber Studies}

Distal colon segments were mounted into $0.1 \mathrm{~cm}^{2}$ aperture sliders bathed in 5-mL baths with oxygenated glucose-fortified Ringers solution for Ussing chamber analysis (Physiologic Instruments) as previously described (14). Briefly, voltage-clamped tissues were equilibrated for $20 \mathrm{~min}$ before baseline transepithelial electrical resistance $\left(\Omega \cdot \mathrm{cm}^{2}\right)$ and short circuit current $\left(\mu \mathrm{A} / \mathrm{cm}^{2}\right)$ were averaged over $10 \mathrm{~min}$.

\section{Myeloperoxidase Activity}

Myeloperoxidase activity in the distal colon was determined as previously described $(15,16)$. Briefly, phosphate-buffered saline-washed tissue segments were homogenized in $0.5 \%$ hexadecyl-trimethylammonium bromide (Sigma-Aldrich) and reacted with $o$-dianisidine hydrochloride (Sigma-Aldrich). Absorbance at $450 \mathrm{~nm}$ was averaged over $5 \mathrm{~min}$ at 30-s intervals. Myeloperoxidase activity is expressed as units/mg of tissue, with 1 unit of myeloperoxidase activity defined as the amount of myeloperoxidase required to degrade $1 \mu \mathrm{mol}$ of peroxide per minute at $25^{\circ} \mathrm{C}$.

\section{IL-1 $\beta$ ELISA}

Proteins were extracted from the distal colon as previously described $(14,15)$. Briefly, colon segments were homogenized for $5 \mathrm{~min}$ in cell extraction buffer (ThermoFisher Scientific) supplemented with protease inhibitor cocktail (Sigma-Aldrich), $1 \mathrm{mM}$ phenyl-methanesulfonyl fluoride (Sigma-Aldrich), and $50 \mu \mathrm{M}$ ethylenediaminetetraacetic acid at 1 $\mathrm{mL} / 50 \mathrm{mg}$ of tissue. The lysate was incubated $\left(1 \mathrm{~h}, 4^{\circ} \mathrm{C}\right.$, with rotation), sonicated ( $2 \mathrm{~min})$, and centrifuged (14,000 rpm, $\left.15 \mathrm{~min}, 4^{\circ} \mathrm{C}\right)$. Supernatant was collected and stored at $-80^{\circ} \mathrm{C}$ until analysis. IL- $1 \beta$ concentrations were determined by OptEIA IL-1 $\beta$ ELISA (BD Biosciences) as previously described $(14,15)$. The limit of sensitivity was less than $4 \mathrm{pg} / \mathrm{mL}$. Concentrations were normalized to total protein concentration as determined by a bicinchoninic acid assay (Abcam) as previously described (15).

\section{Flow Cytometry}

Colon lamina propria mononuclear cells (LPMCs) were isolated enzymatically, essentially as previously described $(14,15)$. Briefly, the colon was excised free of fat and blood vessels, flushed with cold phosphate-buffered saline, roughly chopped, and incubated in 4-(2hydroxyethyl)-1-piperazineethanesulfonic acid buffered Hanks balanced salt solution supplemented with $1 \mathrm{mM}$ ethylenediaminetetraacetic and $1 \mathrm{mM}$ dithiothreitol $\left(20 \mathrm{~min}, 37^{\circ} \mathrm{C}\right.$, gentle shaking). Tissue segments were filtered $(100 \mu \mathrm{M})$, and the remaining tissue was minced and incubated ( $20 \mathrm{~min}, 37^{\circ} \mathrm{C}$, gentle shaking) in complete RPMI 1640 (Gibco) supplemented with fetal calf serum, GlutaMAX (Life Technologies Corp.), penicillin/streptomycin, collagenase D (1 mg/mL), DNAse1 $(0.5 \mathrm{mg} / \mathrm{mL})$, and dispase $(3 \mathrm{mg} / \mathrm{mL}$ ) (all from Sigma-Aldrich) before being strained $(40 \mu \mathrm{M})$ and resuspended over a 40/80 Percoll gradient and the interphase LPMC layer collected and pelleted for LPMCs. Viability was determined (trypan blue), and only preparations with at least $80 \%$ viability were investigated further. $\mathrm{F}_{\mathrm{c}}$-blocked LPMCs $\left(0.5 \times 10^{6}\right)$ were stained with the antimouse monoclonal antibodies CD45-BV605 (30-F11), CD3-BUV395 (145-2C11), and CD11b-APCCy7 (M1/70) (all from BD Biosciences). Per test, 20,000 events were analyzed using a FACS-Fortessa (BD Biosciences), and proportions of live (FVS700; BD Biosciences) singlets were determined using FlowJo (Tree Star), as described previously $(14,15)$.

\section{Antibody-Chelator Conjugation and Radiolabeling}

${ }^{89} \mathrm{Zr}$-oxalate was produced via proton irradiation of ${ }^{89} \mathrm{Y}$ target on a PETtrace 880 cyclotron (GE Healthcare) and purified on Aleco (Comecer) as previously described (17). Monoclonal $\alpha$-CD11b (M1/ 70) and $\alpha$-IL-1 $\beta$ (B122) (BD Biosciences) were conjugated to ${ }^{89} \mathrm{Zr}$ with NCS-Bz-DFO (Macrocyclics) linkage as previously described $(18,19)$. Competitive blocking assays determined the specificity of ${ }^{89} \mathrm{Zr}$-conjugated antibodies, whereby $0.5 \times 10^{6}$ healthy mouse splenocytes were incubated with $1.25 \mu \mathrm{g}$ of ${ }^{89} \mathrm{Zr}$-labeled $\alpha$-IL-1 $\beta$ or $\alpha$-CD11b for $20 \mathrm{~min}$ at $37^{\circ} \mathrm{C}$, in the presence or absence of $50 \mu \mathrm{g}$ of unlabeled $\alpha$-IL-1 $\beta$ or $\alpha$-CD11b added for 20 min beforehand. Cells were pelleted and counted using a Hidex $\gamma$-counter for accumulation of ${ }^{89} \mathrm{Zr}$. All counts were background- and decay-corrected. ${ }^{18} \mathrm{~F}-\mathrm{FDG}$ (phosphate buffer) was produced by the Molecular Imaging and Therapy Research Unit of SAHMRI on a FASTLab synthesizer (GE Healthcare).

\section{MRI-PET}

A 3 to $5 \mathrm{MBq}$ quantity of ${ }^{89} \mathrm{Zr}-\alpha-\mathrm{IL}-1 \beta(37.5 \mu \mathrm{g})$ and ${ }^{89} \mathrm{Zr}-$ $\alpha$-CD11b $(85 \mu \mathrm{g})$ in $100-200 \mu \mathrm{L}$ of saline was administered intravenously (tail vein) $24 \mathrm{~h}$ before imaging, and a 10 to $15 \mathrm{MBq}$ quantity of ${ }^{18} \mathrm{~F}-\mathrm{FDG}$ in $100-200 \mu \mathrm{L}$ of saline was administered intravenously $30 \mathrm{~min}$ before imaging. Some mice underwent MRI first. The mice were anesthetized with isoflurane (2\%), and a T2-weighted rapidacquisition-with-refocused-echoes (RARE) spin-echo sequence was acquired with a benchtop MRI system (Bruker Icon 1T; Bruker Physik $\mathrm{GmbH}$ ) (repetition time, $84 \mathrm{~ms}$; echo time, 4,314 ms; number of excitations, 1; RARE factor, 8 ; field of view, $80 \times 80 \mathrm{~mm}$; slice thickness, $2 \mathrm{~mm}$; scan time, $<2 \mathrm{~min}$ ). ITK snap (www.itksnap.org) was used for consequent segmentation of the scans (20). PET experiments were performed over $15 \mathrm{~min}$ using a submillimeter-resolution $(0.7 \mathrm{~mm})$ Albira PET-SPECT small-animal scanner (Bruker Biospin GmbH). Manually drawn volumes of interest in the area of interest were applied to analyze average and total radiotracer accumulation using the PMOD imaging suite (PMOD Technologies). 


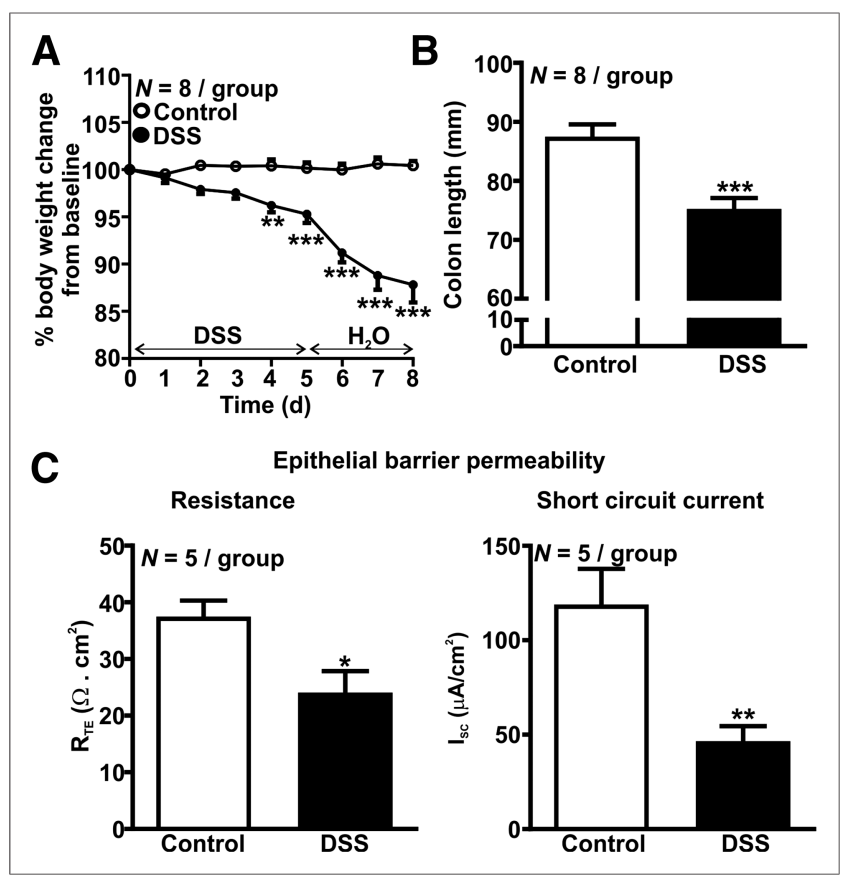

FIGURE 1. Characterization of DSS colitis. (A) Loss of body weight. (B) Shortening of colon length. (C) Impaired epithelial barrier transepithelial electric resistance (left) and short-circuit current (right). ${ }^{*} P<0.05$. ${ }^{\star \star} P<0.01 .{ }^{* \star \star} P<0.001 . \mathrm{R}_{\mathrm{TE}}=$ transepithelial electrical resistance.

\section{Ex Vivo Biodistribution Studies}

Immediately after postimaging culling, organs of interest were dissected, weighed, and counted for ${ }^{89} \mathrm{Zr}$ accumulation as outlined above for blocking experiments.

\section{Statistical Analysis}

Data are expressed as mean \pm SEM in all cases. The significance of results was determined by unpaired $t$ testing except for weight loss data, for which a 2-way ANOVA with Bonferroni post hoc testing was used. The strength and significance of correlations were determined by Pearson analysis. Differences with a $P$ value of less than 0.05 were considered statistically significant.

\section{RESULTS}

\section{DSS Colitis Association with Body Weight Loss, Colon} Shortening, and Impaired Epithelial Permeability

Body weight was reduced in the DSS-treated group $4 \mathrm{~d}$ after treatment began $(P<0.01$, Fig. $1 \mathrm{~A})$ and was further reduced by about $10 \% 8 \mathrm{~d}$ after treatment began $(P<0.001$, Fig. 1A). By day 8 , DSS-treated mice also had approximately $15 \%$ shorter colons $(P<0.001$, Fig. 1B), an approximately $35 \%$ reduction in epithelial resistance $(P<0.01$, Fig. $1 C)$, and an approximately $60 \%$ reduction in short-circuit current $(P<0.01$, Fig. 1C), indicative of colonic inflammation and damage to the epithelial barrier.

\section{Increase in Colonic Innate Immune Infiltration in DSS Colitis}

DSS-treated mice had an approximately 7.5-fold increase in colonic myeloperoxidase activity $(P<0.001$, Fig. 2A) and an approximately 2.5 -fold increase in colonic IL- $1 \beta$ concentration $(P<0.01$, Fig. 2B), indicating that innate immune mediators are increased in colitic mice. The proportion of CD11b colonic LPMCs was increased about 6 -fold in DSS-treated mice $(P<0.001$, Fig. $2 C$ ), indicative of an infiltration by innate myeloid cells, including neutrophils, monocytes, macrophages, and dendritic cells.
Immuno-PET Detection of Colonic Innate Immune Activation in Colitis

${ }^{89} \mathrm{Zr}$ was successfully conjugated to $\alpha-\mathrm{IL}-1 \beta$ and $\alpha-\mathrm{CD} 11 \mathrm{~b}$ as demonstrated by outcompeting binding in the presence of excess unlabeled antibody $\left({ }^{89} \mathrm{Zr}-\alpha-\mathrm{IL}-1 \beta: 8,135 \pm 1,510\right.$ counts per min [cpm] hot vs. $3,026 \pm 337 \mathrm{cpm}$ cold, $P<0.05, n=3$; ${ }^{89} \mathrm{Zr}-$ $\alpha$-CD11b: $61,535 \pm 8,355 \mathrm{cpm}$ hot vs. $34,811 \pm 4,081 \mathrm{cpm}$ cold, $n=3, P<0.05)$. PET imaging revealed that in DSS colitic mice, distal colonic uptake of ${ }^{89} \mathrm{Zr}-\alpha$-IL-1 $\beta$ was increased about 3 -fold $(P<0.001$, Fig. 3A, Supplemental Videos 1 and 2 ; supplemental materials are available at http://jnm.snmjournals.org), ${ }^{89} \mathrm{Zr}-\alpha-\mathrm{CD} 11 \mathrm{~b}$ was increased about 5-fold $(P<0.05$, Fig. 3B, Supplemental Videos 3 and 4$)$, and ${ }^{18}$ F-FDG was increased about 3.5 -fold $(P<0.01$, Fig. $3 \mathrm{C}$, Supplemental Videos 5 and 6). A robust positive correlation $\left(R^{2}=0.70, P<0.05\right)$ was observed between colonic uptake of ${ }^{18} \mathrm{~F}-\mathrm{FDG}$ and percentage body weight loss (Fig. 3C), with a strong trend toward a similar effect observed for ${ }^{89} \mathrm{Zr}-\alpha-\mathrm{IL}-1 \beta\left(R^{2}=0.54\right.$, $P=0.09$, Fig. 3A) but not for ${ }^{89} \mathrm{Zr}-\alpha-\mathrm{CD} 11 \mathrm{~b}$ (Fig. 3B).

\section{Biodistribution of ${ }^{89} \mathrm{Zr}-\alpha-\mathrm{IL}-1 \beta$ and ${ }^{89} \mathrm{Zr}-\alpha-C D 11 b$}

Ex vivo analysis indicated that uptake of ${ }^{89} \mathrm{Zr}-\alpha-\mathrm{IL}-1 \beta$ and ${ }^{89} \mathrm{Zr}-\alpha-\mathrm{CD} 11 \mathrm{~b}$ was increased throughout the gastrointestinal tract in DSS-treated mice relative to control mice but also in some extragastrointestinal sites. Specifically, uptake of ${ }^{89} \mathrm{Zr}-\alpha-\mathrm{IL}-1 \beta$ was increased about 3 -fold in the colon $(P<0.05)$, 5-fold in the cecum $(P<0.01), 1.5$-fold in the small intestine $(P<$ $0.05)$, and 1.75 -fold in the stomach $(P<0.05)$, whereas uptake in the spleen was also increased about 1.75 -fold $(P<0.05)$ (Fig. $4 \mathrm{~A})$. Uptake was similar between DSS-treated and control mice in all other tissues investigated. Uptake of ${ }^{89} \mathrm{Zr}-\alpha-\mathrm{CD} 11 \mathrm{~b}$ was more discrete in the gastrointestinal tract, with increases observed only in the colon $(\sim 26$-fold, $P<0.05)$ and small intestine $(\sim 20$-fold,

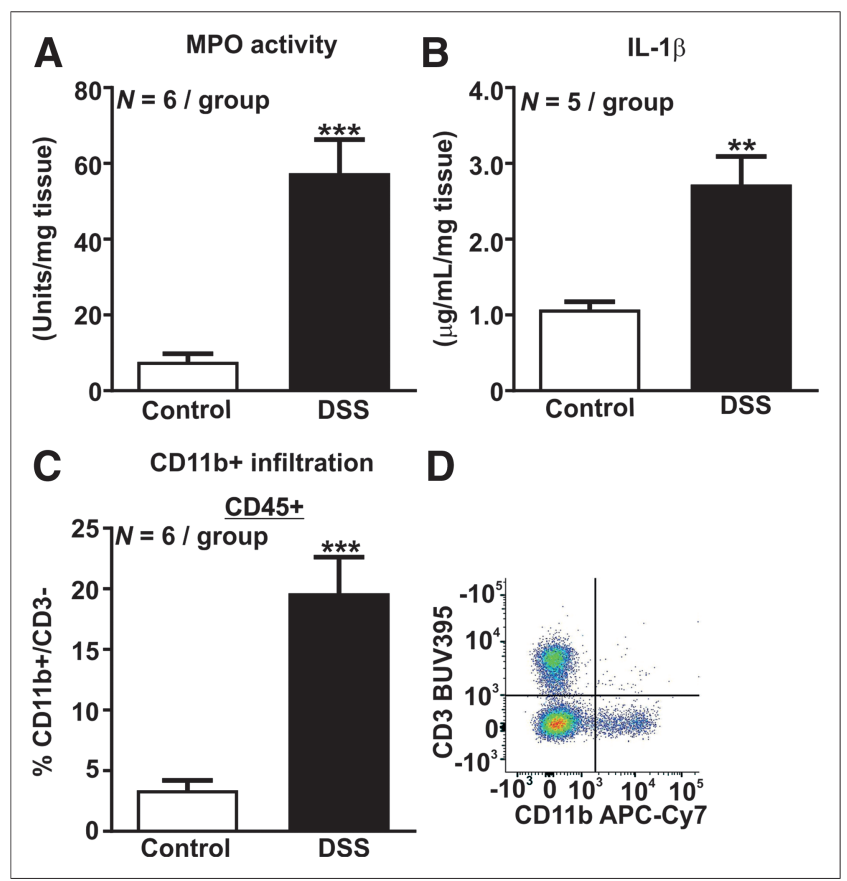

FIGURE 2. Activation of innate immune system by DSS colitis. (A) Increase in colonic myeloperoxidase activity. (B) Increase in IL-1 $\beta$ concentrations. (C) Increase in CD11b-positive CD3-negative innate immune cell infiltration. (D) Gating strategy. ${ }^{\star \star} P<0.01$. ${ }^{\star \star \star} P<0.001$. 


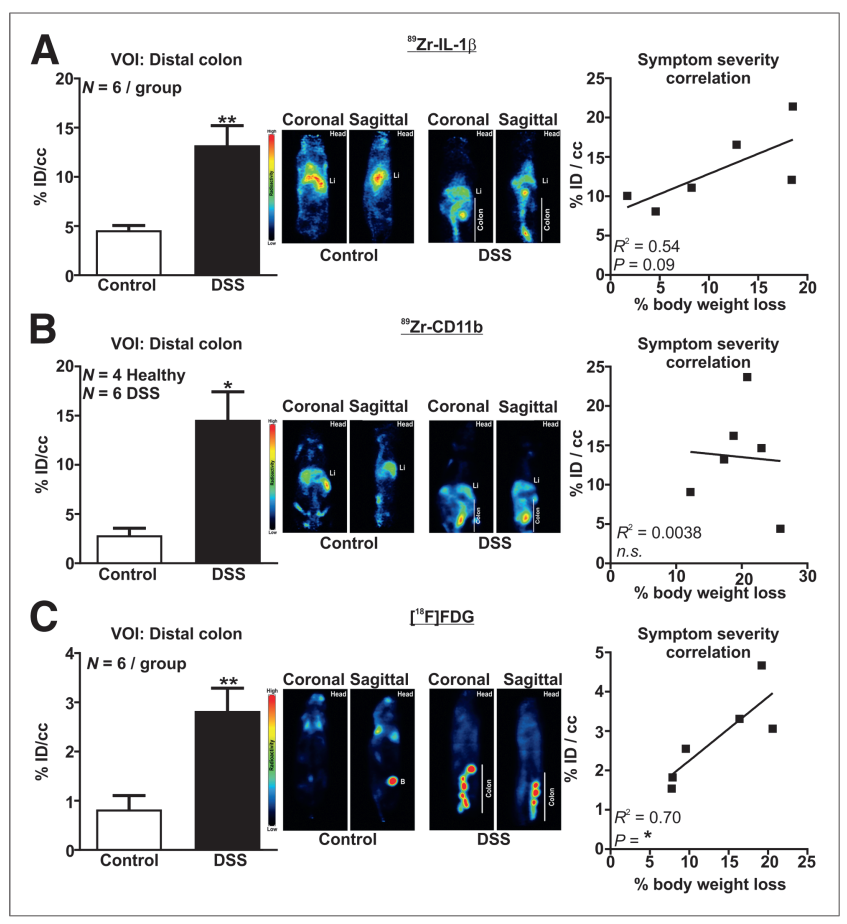

FIGURE 3. $a-I L-1 \beta, a-C D 11 b$, and ${ }^{18}$ F-FDG PET detection of colonic inflammation. Shown are volume-of-interest analysis with representative PET image (coronal and sagittal) of control and DSS mice (left) and correlation of percentage body weight loss with volume of interest (right) for ${ }^{89} \mathrm{Zr}-\mathrm{a}-1 \mathrm{~L}-1 \beta(\mathrm{A}),{ }^{89} \mathrm{Zr}-\mathrm{a}-\mathrm{CD} 11 \mathrm{~b}(\mathrm{~B})$, and ${ }^{18} \mathrm{~F}-\mathrm{FDG}(\mathrm{C}) . \mathrm{Li}=$ liver; $\mathrm{B}=$ bladder; ID = injected dose; n.s. = not statistically significant; $\mathrm{VOI}=$ volume of interest. ${ }^{*} P<0.05 .{ }^{*} P<0.01$.

$P<0.05)$ and a trend toward an increase in the cecum $(\sim 21$-fold, $P=0.083$ ) (Fig. 4B). However, increased uptake of ${ }^{89} \mathrm{Zr}-\alpha-\mathrm{CD} 11 \mathrm{~b}$ was observed in more sites outside the gastrointestinal tract than ${ }^{89} \mathrm{Zr}-\alpha$-IL-1 $\beta$, including approximately 6 -fold in the spleen $(P<$ $0.05)$ but also approximately 7 -fold in the liver $(P<0.05)$ and 8 -fold in the bone marrow $(P<0.05)$. Notably, trends toward increased uptake of ${ }^{89} \mathrm{Zr}-\alpha-\mathrm{CD} 11 \mathrm{~b}$ were observed across most other tissues, including the cecum, tail, and stomach; however, uptake was generally more variable for ${ }^{89} \mathrm{Zr}-\alpha$-CD $11 \mathrm{~b}$ than for ${ }^{89} \mathrm{Zr}-\alpha$-IL$1 \beta$, limiting the significance of these observations.

MRI Detection of Colonic Inflammation in Colitic Mice

MRI analysis of colonic inflammation revealed an approximately 2-fold increase in the $\mathrm{T}_{2}$ signal intensity ratio in DSS colitis relative to control $(P<0.01$, Fig. 5, Supplemental Videos 7 and 8 ), but this analysis did not correlate with percentage body weight loss (Fig. 5).

\section{DISCUSSION}

We demonstrate for the first time, to our knowledge, that immunoPET directed against innate immune cells and mediators is applicable for detection of colitis. The sensitivity of ${ }^{89} \mathrm{Zr}$-labeled $\alpha$-IL-1 $\beta$ and $\alpha$-CD11b immuno-PET for detecting colonic inflammation was similar to that of ${ }^{18} \mathrm{~F}-\mathrm{FDG}$, and all PET approaches were more sensitive than MRI. Furthermore, uptake of ${ }^{89} \mathrm{Zr}-\alpha$-IL-1 $\beta$ was restricted to the gastrointestinal tract and spleen, whereas ${ }^{89} \mathrm{Zr}-\alpha-\mathrm{CD} 11 \mathrm{~b}$ was distributed over a broader range of tissue types. Our comparison demonstrates the strong potential that immuno-PET of innate immune mediators has for diagnosing and monitoring IBD.
Activation of the innate immune system is a hallmark of inflammation in IBD both in humans and in animal models (3,21). DSS is directly toxic to epithelial cells, and we confirm that epithelial damage in DSS colitis is associated with increased colonic infiltration of CD11b-expressing cells and increased colonic concentrations of innate immune cell-secreted IL-1 $\beta$ (22), both of which we were reliably able to detect by PET of ${ }^{89} \mathrm{Zr}$-conjugated monoclonal antibodies. Previous immuno-PET studies have identified increased infiltration of T cells in DSS colitis, either by directly labeling of the $\mathrm{T}_{\text {HELPER }}$ marker CD4 or by labeling of the gut-homing integrin

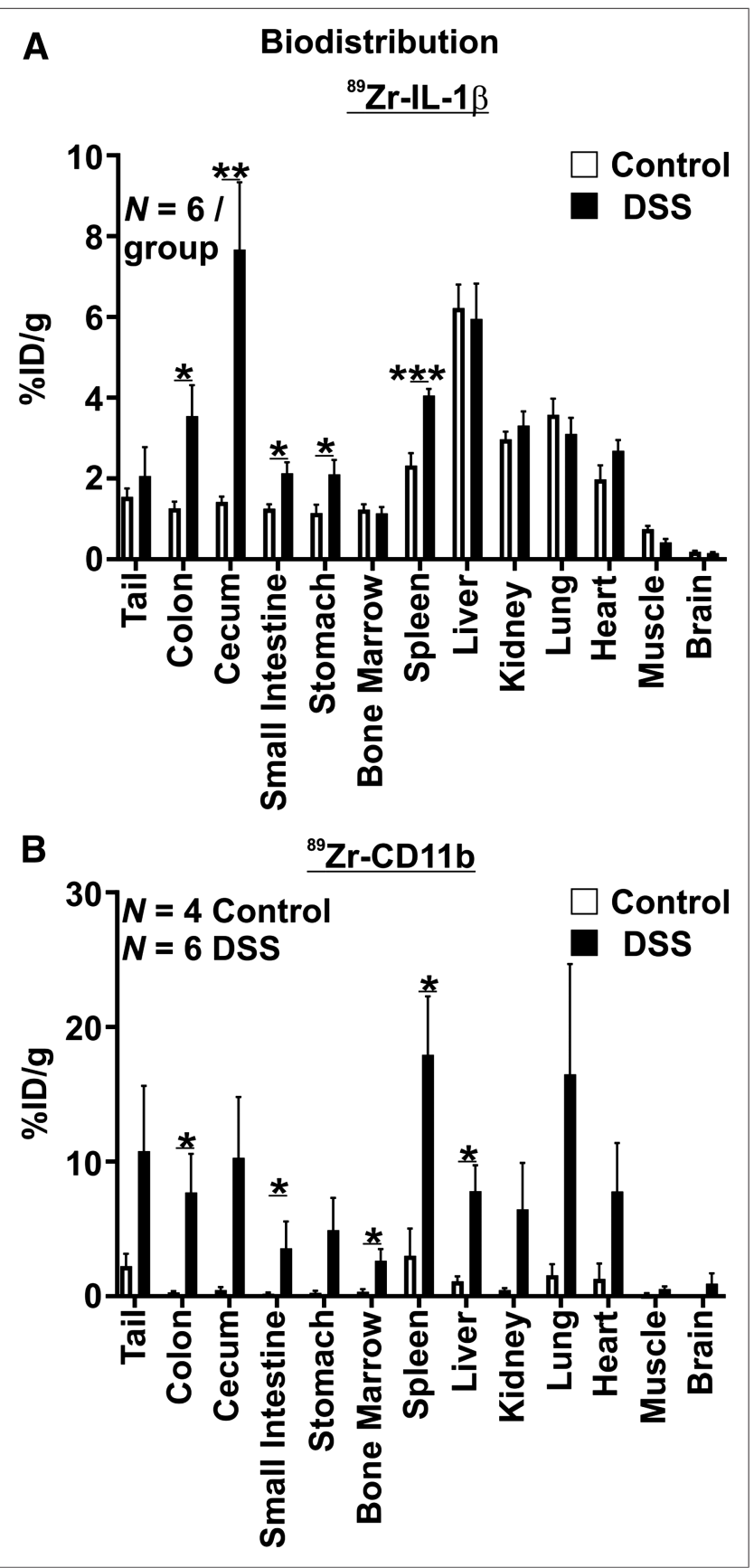

FIGURE 4. Ex vivo biodistribution of ${ }^{89} \mathrm{Zr}-\mathrm{a}-1 \mathrm{~L}-1 \beta$ (A) and ${ }^{89} \mathrm{Zr}$ - $\mathrm{a}-$ CD11b (B). Decay-corrected values for uptake are displayed. ${ }^{*} P<0.05$. ${ }^{\star \star} P<0.01 .{ }^{* \star} P<0.001$. ID $=$ injected dose. 


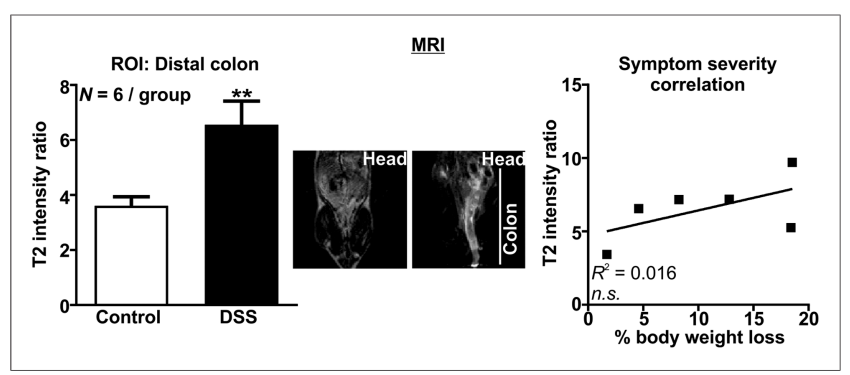

FIGURE 5. MRI detection of colonic inflammation. Region-of-interest analysis with representative MR image (coronal) of control and DSS mice (left) and correlation of percentage body weight loss with regionof-interest MRI analysis (right). ${ }^{\star \star} P<0.01$. n.s. $=$ not statistically significant; $\mathrm{ROI}=$ region of interest.

complex $\alpha_{4} \beta_{7}$, which is upregulated on T cells in $\operatorname{IBD}(9,10,23)$. However, we believe our study to be the first to describe the potential that radiolabeled antibodies against innate immune markers have for PET in IBD diagnosis and monitoring.

We observed a striking difference in the biodistribution of ${ }^{89} \mathrm{Zr}$ $\alpha$-IL-1 $\beta$ and ${ }^{89} \mathrm{Zr}-\alpha-\mathrm{CD} 11 \mathrm{~b}$, with ${ }^{89} \mathrm{Zr}-\alpha$-IL- $1 \beta$ being restricted to the gastrointestinal tract and spleen whereas ${ }^{89} \mathrm{Zr}-\alpha-\mathrm{CD} 11 \mathrm{~b}$ was observed in a broad range of tissues. Furthermore, ${ }^{89} \mathrm{Zr}-\alpha-\mathrm{IL}-1 \beta$ also correlated with colitis severity whereas ${ }^{89} \mathrm{Zr}-\alpha-\mathrm{CD} 11 \mathrm{~b}$ did not. These findings are likely to relate to immunologic processes underlying innate immune activation in colitis. Innate immune cells migrate from induction sites in lymphatic tissue through the bloodstream into sites of inflammation, where they mature and secrete cytokines, including IL-1 $\beta$, before clearing from tissue by the lymphatics or dying (24). CD11b is expressed on innate cell subsets that promote inflammation, such as M1 macrophages and most neutrophil subsets, but also on innate immune cells that promote tolerance, wound healing, and immune suppression, including M2 macrophages, dendritic cells, and CXCL4-expressing neutrophil subsets $(25,26)$. These cells express CD11b at all stages of maturity, and imaging CD11b is therefore likely to detect sites of inflammation but also migration between tissues and lymph nodes, including the bone marrow and, particularly in mice, the spleen. Furthermore, whereas CD11b expression is high on myeloid innate immune cells, it is also expressed on other immune cells, including T- and B-cell subsets, which may contribute toward the signal we observed in our imaging (27). The expression of individual markers on multiple cell types is common; for example, CD4 is expressed on macrophages in addition to $\mathrm{T}_{\text {HELPER }}$ cells, and complex flow cytometry using multiple markers is typically required to conclusively characterize individual immune cell subsets. For IBD, this is particularly relevant to the everexpanding $\mathrm{T}_{\text {HELPER }}$ cell subsets and innate lymphoid cells, which rely on staining of cytoplasmic cytokines or nuclear transcription factors for their characterization (28). Definitively identifying these subsets for in vivo imaging is difficult in live cells because antibodies are typically too large to passively enter cells.

In contrast, IL- $1 \beta$ has 2 favorable characteristics for immunoPET. First, it is inducible rather than constitutive and therefore is secreted only by activated cells, which, in colitis, are predominately located at sites of inflammation. Second, proteolytic processing of IL-1 $\beta$ into its mature form typically occurs within the cell, and it is secreted as a mature functional protein (29). This is somewhat an anomaly for cytokines but is beneficial for immunoPET because only mature IL- $1 \beta$ is imaged. Our results support further investigation into the use of imaging inducible and intracellularly processed immune mediators for detecting inflammation in IBD. Furthermore, immuno-PET using radiolabels with long halflives, such as ${ }^{89} \mathrm{Zr}$, enables longitudinal imaging, which would provide valuable information on the temporal nature of immune responses in IBD.

SPECT is a cost-effective technique for nuclear imaging but generally has reduced resolution relative to PET. Nonetheless, SPECT imaging of the neutrophil-attracting chemokine CXCL8, and CD4, has also shown potential in preclinical and human studies of IBD $(11,12,30)$. Furthermore, whereas SPECT imaging of the TNF$\alpha$-neutralizing antibody infliximab also demonstrated some efficacy in preclinical colitis, it was hindered by high background, the cause of which was likely its chimeric mouse-human properties (13). The most readily available alternative markers for immunoPET imaging of IBD include antibodies that are currently used for treatment, including variations targeting TNF- $\alpha, \alpha_{4} \beta_{7}$ (vedolizumab), $\alpha_{4} \beta_{1}$ (natalizumab), and IL-12/23 (ustekinumab) (31). However, markers do not have to be limited to the immune system. Epithelial damage and increased epithelial barrier permeability are hallmarks of IBD and colitis, as we demonstrate in our model $(32,33)$. The permeability of the epithelial monolayer to luminal contents is regulated by a large family of tight-junction proteins, many of which are reduced in degraded tissue in the inflamed intestine, impeding their use as markers. Conversely, expression of some of these proteins promotes increased permeability and is increased during IBD, such as the pore-forming claudin-2 (34,35). Other potential markers include those associated with tissue remodeling associated with the resolution of inflammation (36). Matrix metalloproteases are involved in tissue remodeling and, interestingly, are thought to play a key role in promoting fibrosis. Although an antibody against matrix metalloprotease 9 was ultimately withdrawn from clinical trials on IBD, interest in this target remains and it may have more promise as a marker of fibrosis (37).

The clinical utility of immuno-PET for IBD is currently limited by several issues. Primarily, antibodies are large molecules with molecular weights of about $150 \mathrm{kDa}$. This large size prolongs their half-life and reduces excretion, which is beneficial when used as treatments but is challenging for imaging because tissue penetration is reduced and excretion prolonged. Issues related to tissue penetration may be somewhat diminished in IBD because vascular permeability is increased in inflammation, aiding immune cell migration into inflammatory sites (38). However, increased leukocyte extravasation is unlikely to drastically reduce the time taken for systemically administered antibodies to reach inflammatory sites in IBD, and the current clinical paradigm would require dosing and imaging to occur at separate visits over several days. This requirement results in increased exposure to radiolabels, potentially increasing the risk of side effects. Promising alternatives to intact antibodies that potentially limit these concerns are in development (39). Notably, engineered small antibody fragments against anti-CD4 and $\beta_{7}$ have already shown promise in preclinical colitis $(9,10)$. A different strategy uses a 2-step process for pretargeting. The initial step comprises administration of an antibody modified to incorporate a radiolabel capture site, which is allowed enough time to localize to its target. A few days later, the radiolabel is injected and binds to the antibody. This strategy has shown promise in cancer (40) but has yet to be applied to IBD and may prove difficult because the harsh protease-rich environment in inflammation may rapidly degrade targets. 


\section{CONCLUSION}

We have demonstrated that radiolabeled antibodies against innate immune cells and mediators are suitable for immuno-PET of colitis. Our results provide further evidence of the clinical utility of immuno-PET for IBD diagnosis and monitoring. Development of these techniques would be of particular benefit to patients who are difficult to scope, including the pediatric population and those that have inflamed or fibrotic regions of the small intestine.

\section{DISCLOSURE}

This study was funded by a project development grant to the University of Adelaide, with ${ }^{89} \mathrm{Zr}$ radiochemistry supported by Bellberry Limited and the Bellberry Molecular Imaging Program. Further support was provided by an Australian Government research training program and a William T. Southcott Nuclear Medicine Scholarship to Nicole Dmochowska, an NHMRC C.J. Martin Biomedical Fellowship (APP1140992) to Hannah Wardill, and an NHMRC R.D. Wright Biomedical Research Fellowship (APP1105028) to Patrick Hughes. No other potential conflict of interest relevant to this article was reported.

\section{ACKNOWLEDGMENTS}

We acknowledge the facilities and scientific and technical assistance of the National Imaging Facility, a National Collaborative Research Infrastructure Strategy (NCRIS) capability, at SAHMRI.

\section{REFERENCES}

1. Abraham C, Cho JH. Inflammatory bowel disease. N Engl J Med. 2009;361: 2066-2078.

2. Baumgart DC, Sandborn WJ. Inflammatory bowel disease: clinical aspects and established and evolving therapies. Lancet. 2007;369:1641-1657.

3. Sands BE. Biomarkers of inflammation in inflammatory bowel disease. Gastroenterology. 2015;149:1275-1285.e2.

4. Caobelli F, Evangelista L, Quartuccio N, et al. Role of molecular imaging in the management of patients affected by inflammatory bowel disease: state-of-the-art. World J Radiol. 2016;8:829-845.

5. Allocca M, Fiorino G, Bonifacio C, et al. Comparative accuracy of bowel ultrasound versus magnetic resonance enterography in combination with colonoscopy in assessing Crohn's disease and guiding clinical decision-making. J Crohns Colitis. 2018;12:1280-1287.

6. Knowles SM, Wu AM. Advances in immuno-positron emission tomography: antibodies for molecular imaging in oncology. J Clin Oncol. 2012;30:38843892 .

7. van Dongen GA, Visser GW, Lub-de Hooge MN, de Vries EG, Perk LR. Immuno-PET: a navigator in monoclonal antibody development and applications. Oncologist. 2007;12:1379-1389.

8. Bailly C, Clery PF, Faivre-Chauvet A, et al. Immuno-PET for clinical theranostic approaches. Int J Mol Sci. 2016;18:E57.

9. Freise AC, Zettlitz KA, Salazar FB, et al. Immuno-PET in inflammatory bowel disease: imaging CD4-positive T cells in a murine model of colitis. J Nucl Med. 2018;59:980-985.

10. Dearling JL, Daka A, Veiga N, Peer D, Packard AB. Colitis immunoPET: defining target cell populations and optimizing pharmacokinetics. Inflamm Bowel Dis. 2016;22:529-538.

11. Gratz S, Rennen HJ, Boerman OC, Oyen WJ, Corstens FH. Rapid imaging of experimental colitis with ${ }^{99 \mathrm{~m}}$ Tc-interleukin-8 in rabbits. $J$ Nucl Med. 2001;42: 917-923.

12. Aarntzen EH, Hermsen R, Drenth JP, Boerman OC, Oyen WJ. ${ }^{99 \mathrm{~m}} \mathrm{Tc}$-CXCL8 SPECT to monitor disease activity in inflammatory bowel disease. $\mathrm{J} \mathrm{Nucl} \mathrm{Med}$. 2016;57:398-403.

13. Tsopelas C, Penglis S, Ruskiewicz A, Bartholomeusz DL. Scintigraphic imaging of experimental colitis with technetium-99m-infliximab in the rat. Hell J Nucl Med. 2006;9:85-89.
14. Hofma BR, Wardill HR, Mavrangelos C, et al. Colonic migrating motor complexes are inhibited in acute tri-nitro benzene sulphonic acid colitis. PLoS One. 2018;13:e0199394.

15. Campaniello MA, Mavrangelos C, Eade S, et al. Acute colitis chronically alters immune infiltration mechanisms and sensory neuro-immune interactions. Brain Behav Immun. 2017;60:319-332.

16. Campaniello MA, Harrington AM, Martin CM, Ashley Blackshaw L, Brierley SM, Hughes PA. Activation of colo-rectal high-threshold afferent nerves by interleukin2 is tetrodotoxin-sensitive and upregulated in a mouse model of chronic visceral hypersensitivity. Neurogastroenterol Motil. 2016;28:54-63.

17. Holland JP, Sheh Y, Lewis JS. Standardized methods for the production of high specific-activity zirconium-89. Nucl Med Biol. 2009;36:729-739.

18. Vosjan MJ, Perk LR, Visser GW, et al. Conjugation and radiolabeling of monoclonal antibodies with zirconium-89 for PET imaging using the bifunctional chelate p-isothiocyanatobenzyl-desferrioxamine. Nat Protoc. 2010;5:739-743.

19. Holland JP, Divilov V, Bander NH, Smith-Jones PM, Larson SM, Lewis JS. ${ }^{89} \mathrm{Zr}-$ DFO-J591 for immunoPET of prostate-specific membrane antigen expression in vivo. J Nucl Med. 2010;51:1293-1300.

20. Yushkevich PA, Piven J, Hazlett HC, et al. User-guided 3D active contour segmentation of anatomical structures: significantly improved efficiency and reliability. Neuroimage. 2006;31:1116-1128.

21. Neurath MF. Cytokines in inflammatory bowel disease. Nat Rev Immunol. 2014;14: 329-342.

22. Kiesler P, Fuss IJ, Strober W. Experimental models of inflammatory bowel diseases. Cell Mol Gastroenterol Hepatol. 2015;1:154-170.

23. Rivera-Nieves J. Strategies that target leukocyte traffic in inflammatory bowel diseases: recent developments. Curr Opin Gastroenterol. 2015;31:441-448.

24. Mowat AM, Agace WW. Regional specialization within the intestinal immune system. Nat Rev Immunol. 2014;14:667-685.

25. Ehirchiou D, Xiong Y, Xu G, Chen W, Shi Y, Zhang L. CD11b facilitates the development of peripheral tolerance by suppressing Th17 differentiation. $J$ Exp Med. 2007;204:1519-1524.

26. Shen S, Prame Kumar K, Stanley D, et al. Invariant natural killer T cells shape the gut microbiota and regulate neutrophil recruitment and function during intestinal inflammation. Front Immunol. 2018;9:999.

27. Zola H, Swart B, Nicholson I, Voss E. Leukocyte and Stomal Cell Markers: The CD Markers. Hoboken, New Jersey: John Wiley and Sons, Inc.; 2006:58-59.

28. Goldberg R, Prescott N, Lord GM, MacDonald TT, Powell N. The unusual suspects: innate lymphoid cells as novel therapeutic targets in IBD. Nat Rev Gastroenterol Hepatol. 2015;12:271-283.

29. Afonina IS, Muller C, Martin SJ, Beyaert R. Proteolytic processing of interleukin1 family cytokines: variations on a common theme. Immunity. 2015;42:991-1004.

30. Kanwar B, Gao DW, Hwang AB, et al. In vivo imaging of mucosal CD4+ T cells using single photon emission computed tomography in a murine model of colitis. J Immunol Methods. 2008;329:21-30.

31. Danese S, Vuitton L, Peyrin-Biroulet L. Biologic agents for IBD: practical insights. Nat Rev Gastroenterol Hepatol. 2015;12:537-545.

32. Ahmad R, Sorrell MF, Batra SK, Dhawan P, Singh AB. Gut permeability and mucosal inflammation: bad, good or context dependent. Mucosal Immunol. 2017; 10:307-317.

33. McGuckin MA, Eri R, Simms LA, Florin TH, Radford-Smith G. Intestinal barrier dysfunction in inflammatory bowel diseases. Inflamm Bowel Dis. 2009;15:100-113.

34. Landy J, Ronde E, English N, et al. Tight junctions in inflammatory bowel diseases and inflammatory bowel disease associated colorectal cancer. World $J$ Gastroenterol. 2016;22:3117-3126.

35. Luissint AC, Parkos CA, Nusrat A. Inflammation and the intestinal barrier: leukocyte-epithelial cell interactions, cell junction remodeling, and mucosal repair. Gastroenterology. 2016;151:616-632.

36. Lawrance IC, Rogler G, Bamias G, et al. Cellular and molecular mediators of intestinal fibrosis. J Crohns Colitis. 2017;11:1491-1503.

37. Neurath M. Current and emerging therapeutic targets for IBD. Nat Rev Gastroenterol Hepatol. 2017;14:688.

38. Rampton DS, Collins CE. Review article: thromboxanes in inflammatory bowel disease-pathogenic and therapeutic implications. Aliment Pharmacol Ther. 1993; 7:357-367.

39. Freise $\mathrm{AC}, \mathrm{Wu} \mathrm{AM}$. In vivo imaging with antibodies and engineered fragments. Mol Immunol. 2015;67:142-152.

40. Foubert F, Gouard S, Sai-Maurel C, et al. Sensitivity of pretargeted immunoPET using ${ }^{68} \mathrm{Ga}$-peptide to detect colonic carcinoma liver metastases in a murine xenograft model: comparison with ${ }^{18}$ FDG PET-CT. Oncotarget. 2018;9:2750227513. 